\title{
Sources of acoustic emission during fatigue of Ti-6AI-4V: effect of microstructure
}

\author{
D. H. KOHN*, P. DUCHEYNE \\ Department of Bioengineering, University of Pennsylvania, Philadelphia, Pennsylvania \\ 19104-6392, USA \\ J. AWERBUCH \\ Department of Mechanical Engineering and Mechanics, Drexel University, Philadelphia, \\ Pennsylvania 19104, USA
}

\begin{abstract}
The fundamentals of acoustic emission $(A E)$ analysis of fatigue cracking were applied to $\mathrm{Ti}-6 \mathrm{Al}-4 \mathrm{~V}$. The effect of microstructure on the characteristics of the $A E$ events generated and the failure mechanisms which produced $\mathrm{AE}$ in $\mathrm{Ti}-6 \mathrm{Al}-4 \mathrm{~V}$ were established. Lamellar microstructures generated one to two orders of magnitude more emission than equiaxed microstructures. The combination of larger grain size, more continuous $\alpha / \beta$ interfaces, more tortuous crack-front geometry, cleavage and intergranular fracture in lamellar microstructures accounts for the greater amount of emission. For lamellar microstructures, most AE events were generated in the upper $20 \%$ of the stress range, whereas in equiaxed microstructures, most events were generated at lower stresses. Most AE events were generated during crack opening and also at low stresses. AE events having high level intensities were also generated at stresses other than the peak stress. This is because in titanium alloys, which have both high strength and toughness, $A E$ events are generated from both plastic zone extension and crack extènsion.
\end{abstract}

\section{Introduction}

The fatigue life of a component can be divided into two stages, fatigue-crack initiation and fatigue-crack propagation, each often governed by different mechanisms. For $\alpha+\beta$ titanium alloys, microstructures with a small $(<20 \mu \mathrm{m}) \alpha$-grain size, a well dispersed $\beta$-phase and a small $\alpha / \beta$ interface area, such as equiaxed microstructures, resist fatigue-crack initiation best, and have the greatest fatigue strength [1-4]. On the other hand, microstructures with large grains and large $\alpha / \beta$ interfacial areas, such as lamellar microstructures, have the lowest fatigue-crack propagation rates and highest threshold-stress intensities $\left(\Delta K_{\mathrm{th}}\right)$ [1-5]. Since there are conflicting microstructural requirements for fatigue-crack initiation and propagation resistance, a method of differentiating between initiation and propagation represents an essential step in optimizing the fatigue strength of a component.

We consider acoustic emission (AE) an excellent method of differentiating initiation from propagation, since our previous work $[6,7]$ has shown that $\mathrm{AE}$ can detect incipient fatigue crack extensions of less than $10 \mu \mathrm{m}$ in Ti-6Al-4V. Based on this sensitivity, crack initiation is defined as the nucleation of an acoustically detectable (mode I) fatigue crack, on the order of the $\alpha$-grain size. AE has also been used by others during mechanical testing of titanium-based materials
[8-14]. However, most of these studies focused on static loading.

Tanaka and Horiuchi [8] showed that peak AE event amplitude increased with increasing grain size during tensile deformation of pure titanium, with grain sizes of $55 \mu \mathrm{m}$ generating an order of magnitude more AE than $10 \mu \mathrm{m}$ grain sizes. Kennedy [9] showed that $\beta$-annealed $\mathrm{Ti}-6 \mathrm{Al}-4 \mathrm{~V}$ generated one to two orders of magnitude more $\mathrm{AE}$ events than millannealed or recrystallized Ti-6Al-4V during tensile deformation. Mill-annealed and recrystallized microstructures had less scatter in the acoustical data than $\beta$-annealed microstructures, because there was less scatter in the mechanical data. Similar findings were found by Chancy et al. [10], and Friesel and Carpenter [11], who showed that twinning contributions to emission increased with increasing grain size, and that the increased twinning produced larger peaksignal amplitudes.

Kishi et al. $[12,13]$ used AE to detect the onset of slow crack growth and study failure mechanisms during fracture toughness testing of Ti-6Al-4V. The AE event count rate and peak-signal amplitude increased just before the stress intensity factor reached its critical value $\left(K_{\mathrm{Ic}}\right)$. Small amplitude signals prior to $K_{\mathrm{Ic}}$ were attributed to microcracking and cracking of inclusions and $\alpha / \beta$ phase boundaries. The AE events generated in 
equiaxed microstructures were fewer in number and lower in energy than events generated in lamellar microstructures, and no large amplitude AE events were detected prior to $K_{\mathrm{Ic}}$.

Yuyama et al. [14] studied corrosion fatigue and stress corrosion cracking in equiaxed $\mathrm{Ti}-6 \mathrm{Al}-4 \mathrm{~V}$. Although the crack-growth rate was independent of testing environment, greater $\mathrm{AE}$ event counts, count rates and peak-signal amplitudes were recorded during testing in $\mathrm{NaCl}$ solution. The implication of this result is that the $\mathrm{AE}$ technique is able to detect microscopic failure processes during fatigue which traditional macroscopic monitoring techniques cannot detect. By relating peak AE event amplitudes to observed forms of cracking, it was determined that intergranular cracks produced the most $\mathrm{AE}$, followed by $\alpha / \beta$ interface cracks and transgranular cracks.

Aside from the work of Yuyama et al. [14], few studies have analysed the characteristics of the AE generated during fatigue of titanium alloys, the source mechanisms responsible for the AE generation, or the relationship between the $\mathrm{AE}$ generated and the source mechanisms. Accordingly, it is the objective of this paper to apply the fundamentals of $\mathrm{AE}$ monitoring, previously described [7], to analyse fatigue cracking of Ti-6Al-4V. Specifically, two questions are addressed: (i) how does the microstructure of Ti-6Al-4V (equiaxed against lamellar) affect the $\mathrm{AE}$ generated? and (ii) what are the mechanisms which produce AE during fatigue crack initiation and propagation in Ti-6Al-4V?

\section{Materials and methods}

\subsection{Materials and specimen types}

Specimens were obtained from $3.2 \mathrm{~mm}$ thick forgedannealed, extra-low-interstitial (ELI) Ti-6Al-4V plate material with an equiaxed $\alpha+\beta$ microstructure. The chemical composition of the as-received material (Table I) conformed to ASTM F-136 [15]. Specimens were machined so that the direction of loading was parallel to the rolling axis of the plate. The specimen geometry and dimensions are indicated in Fig. 1. Specimens with two types of microstructures were tested: the as-received, equiaxed $\alpha+\beta$ structure, and an $\alpha+\beta$ lamellar structure, achieved by $\beta$-annealing (Fig. 2).

TABLE I Chemical compositions of as-received $\mathrm{Ti}-6 \mathrm{Al}-4 \mathrm{~V}^{\mathrm{a}}$

\begin{tabular}{lll}
\hline Element & As-received (wt \%) & ASTM F136-84 (wt \%) \\
\hline $\mathrm{N}_{2}$ & 0.015 & $0.05(\max )$ \\
$\mathrm{C}$ & 0.010 & $0.08(\max )$ \\
$\mathrm{H}_{2}$ & 0.007 & $0.012(\max )$ \\
$\mathrm{Fe}$ & 0.150 & $0.25(\max )$ \\
$\mathrm{O}_{2}$ & 0.112 & $0.13(\max )$ \\
$\mathrm{Al}$ & 5.90 & $5.50-6.50$ \\
$\mathrm{~V}$ & 3.50 & $3.50-4.50$ \\
$\mathrm{Ti}$ & Balance & Balance
\end{tabular}

${ }^{\text {a }}$ Chemical analysis of $\mathrm{Ti}-6 \mathrm{Al}-4 \mathrm{~V}$ supplied by Titanium Industries Central Service Center, Shaumburg, Illinois, USA.

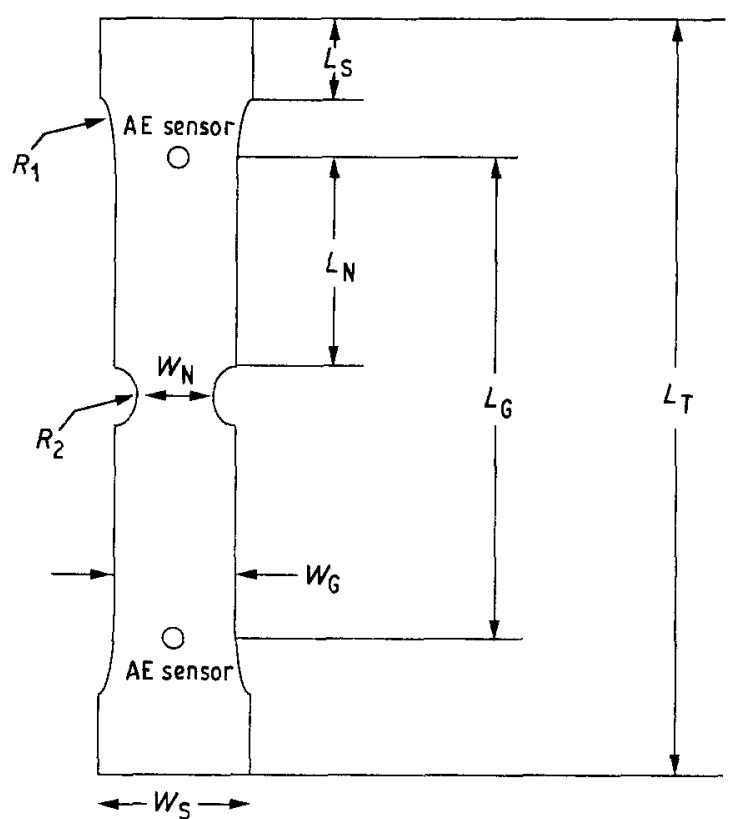

Figure 1 Schematic of AE specimen design. Dimensions (mm) $L_{\mathrm{T}}=387.5 ; L_{\mathrm{G}}=239 ; L_{\mathrm{N}}=107 ; L_{\mathrm{S}}=50 ; W_{\mathrm{S}}=50 ; W_{\mathrm{G}}=37.5$ $W_{\mathrm{N}}=25 ; R_{1}=50 ; R_{2}=15.6$.
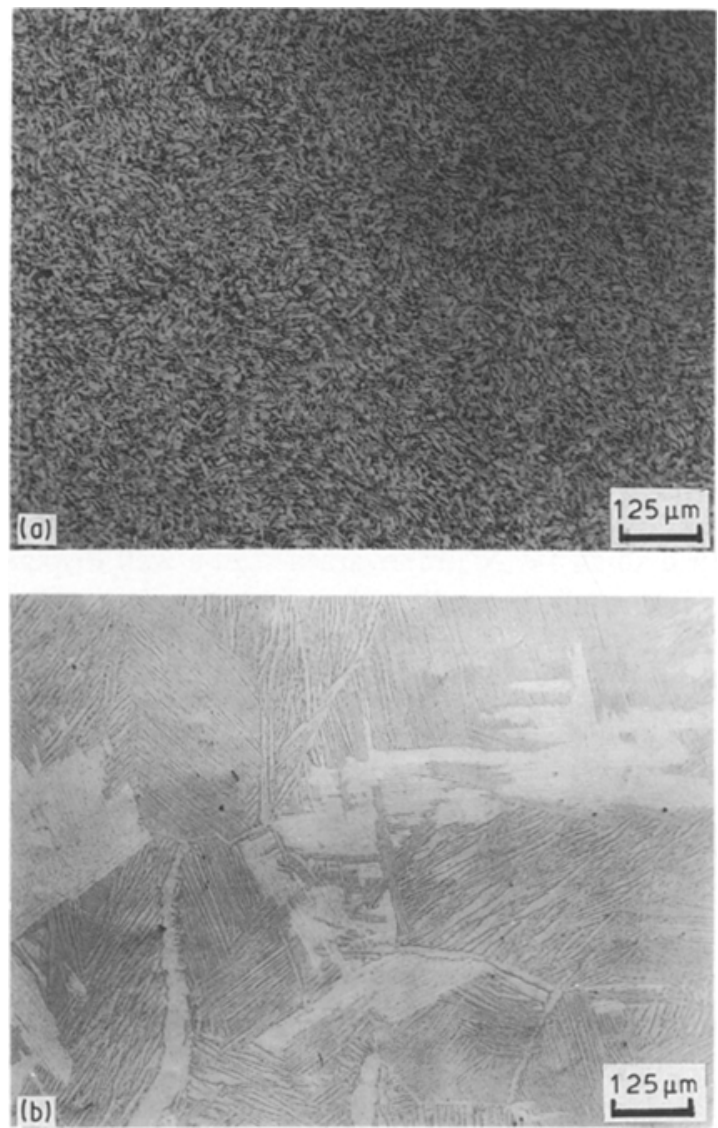

Figure 2 Light micrographs of (a) equiaxed and (b) lamellar Ti-6Al-4V $(200 \times)$.

\subsection{Fatigue testing procedure and $A E$ data acquisition}

Tension-tension fatigue tests $(R=0.1)$ were performed using a closed loop servo-hydraulic mechanical testing machine (Instron Model 1331, Canton, MA, USA). Tests were conducted under load-controlled 
TABLE II AE instrumentation and operating parameters

\begin{tabular}{ll}
\hline Transducers & PZ Type R-15 \\
& $150 \mathrm{kHz}$ res. freq. \\
Pre-amplifier & Model 1220A \\
& $40 \mathrm{~dB}$ fixed gain \\
& $100-300 \mathrm{kHz}$ filter \\
Post-amplifier & $40 \mathrm{~dB}$ gain \\
Threshold & $1.0 \mathrm{~V}$ \\
Dead time & $1 \mathrm{~ms}$ \\
Time base & $0.1 \times$ frequency $^{-1} \mathrm{~s}$ \\
\hline
\end{tabular}

mode, with a sinusoidal load cycle, at different frequencies ranging from $0.1-1.0 \mathrm{~Hz}$. For most tests, the maximum stress was $70 \%$ of the ultimate strength of the respective microstructures $(600-730 \mathrm{MPa})$. Prior to the first fatigue cycle, the specimens were statically loaded (under stroke control at a rate of $0.05 \mathrm{~mm} \mathrm{~min}^{-1}$ ) to determine if there were any flaws in the material which might be sources of AE. The amount of damage accumulation from these flaws during the initial loading was therefore determined.

Two AE sensors were mounted, equidistant from the reduced gauge section, onto the two neck regions of the specimens (Fig. 1). After cleaning the specimens with acetone, the transducers were coupled to the specimens with a water-soluble acoustic couplant (Dunegan/Endevco AC-WS) and fixed in place by using duct tape.

AE was monitored with Physical Acoustics Corporation (PAC, Princeton, NJ, USA) 3000/3004 instrumentation. The pertinent operating parameters are listed in Table II. Detailed post-test analyses included linear source location, number of AE events, and $\mathrm{AE}$ event intensities (e.g. event amplitude (Amp), counts (Cts), duration (Dur) and energy counts (En Cts). The specific data analysis techniques employed to relate $\mathrm{AE}$ event characteristics to material variables and failure mechanisms are described in detail elsewhere [7].

Monitoring of fatigue crack propagation was also performed optically through a closed circuit television system. A video camera (Panasonic Intralux 6000, 30 frames $\mathrm{s}^{-1}$, Philadelphia, PA, USA) with a high magnification $(\times 125)$ microscope zoom lens was used for visual inspection of the entire width and reduced gauge length of the specimen for surface cracks. Fatigue crack propagation was recorded onto a video cassette recorder for post-test correspondence with the AE data.

\subsection{Fractographic analysis}

Fatigue fracture surfaces were analysed using a scanning electron microscope (Phillips 500 SEM, Eindhoven, Netherlands) and related to $\mathrm{AE}$ event accumulation rates and intensities as follows. Crack lengths were measured in the SEM and related to the crack length and fatigue-cycle number on the videotapes of crack growth. Since fatigue-cycle number was also recorded during $\mathrm{AE}$ data acquisition, fracturesurface morphologies could then be related to $\mathrm{AE}$ signal characteristics.

\section{Results and discussion}

\subsection{Effect of microstructure on $A E$}

Representative curves of cumulative number of $\mathrm{AE}$ events as a function of cumulative number of fatigue cycles ( $E-N$ curves) recorded for equiaxed (Fig. 3a) and lamellar specimens (Fig. 3b) had similar characteristics. Therefore the three stages of AE, representing crack initiation, slow and rapid crack propagation as previously described [7], were detected, enabling failure to be readily anticipated for both classes of microstructure.

As the $E-N$ curves for the rapid crack propagation stage of fatigue (Fig. 4) show, the biggest difference between the two microstructures is in the amount of AE generated. Lamellar microstructures generated one to two orders of magnitude more $\mathrm{AE}$ than equiaxed microstructures.

The location distribution histograms (LDH) (Fig. 5) reveal that there was continuous emission generated within the reduced gauge section for both microstructures. Most of the events generated from the equiaxed specimens were at the crack tip. However, for the lamellar samples, sporadic single events occurred at other locations along the specimen. These $\mathrm{AE}$ events generated away from the crack tip in lamellar
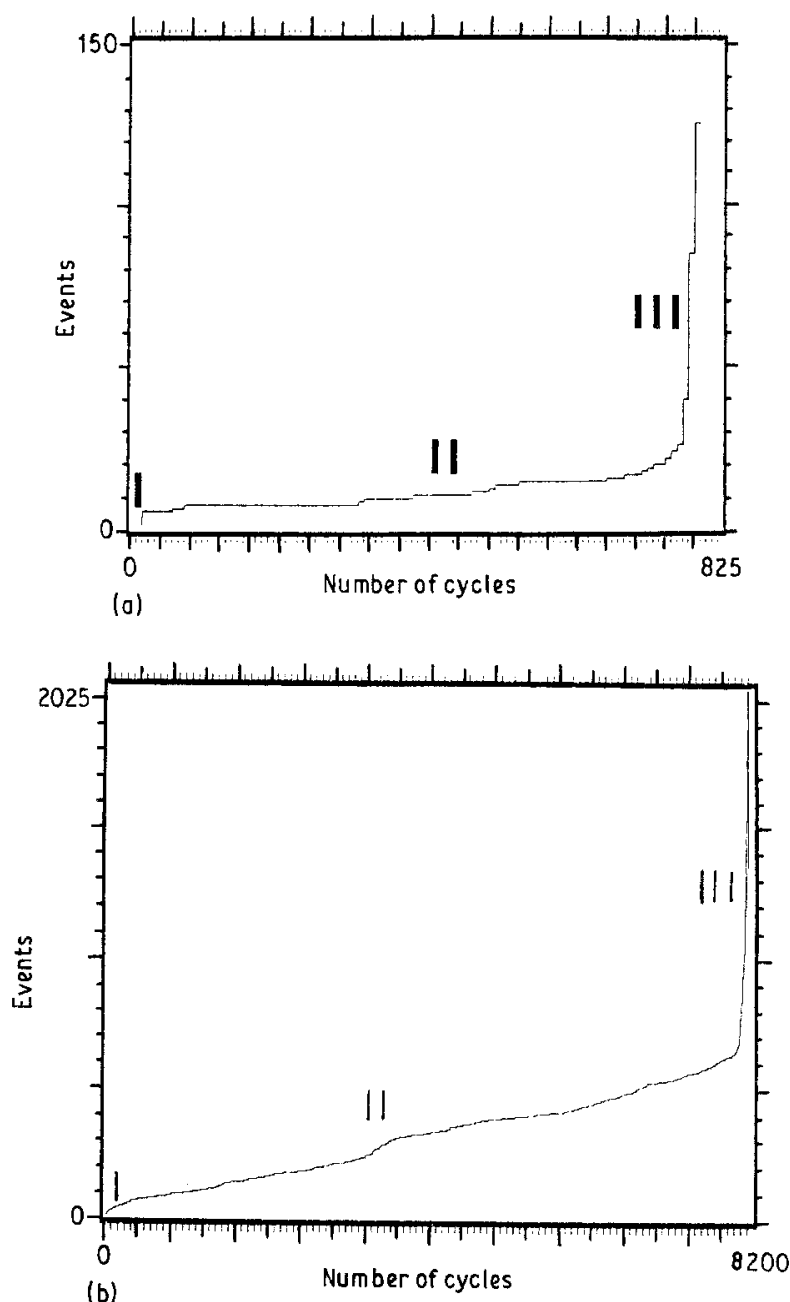

Figure 3 Representative curves of cumulative number of AE events as a function of cumulative number of fatigue cycles ( $E-N$ curves) for (a) equiaxed and (b) lamellar microstructures, showing three stages of AE: crack initiation (I), slow-crack propagation (II) and rapid-crack propagation (III). 

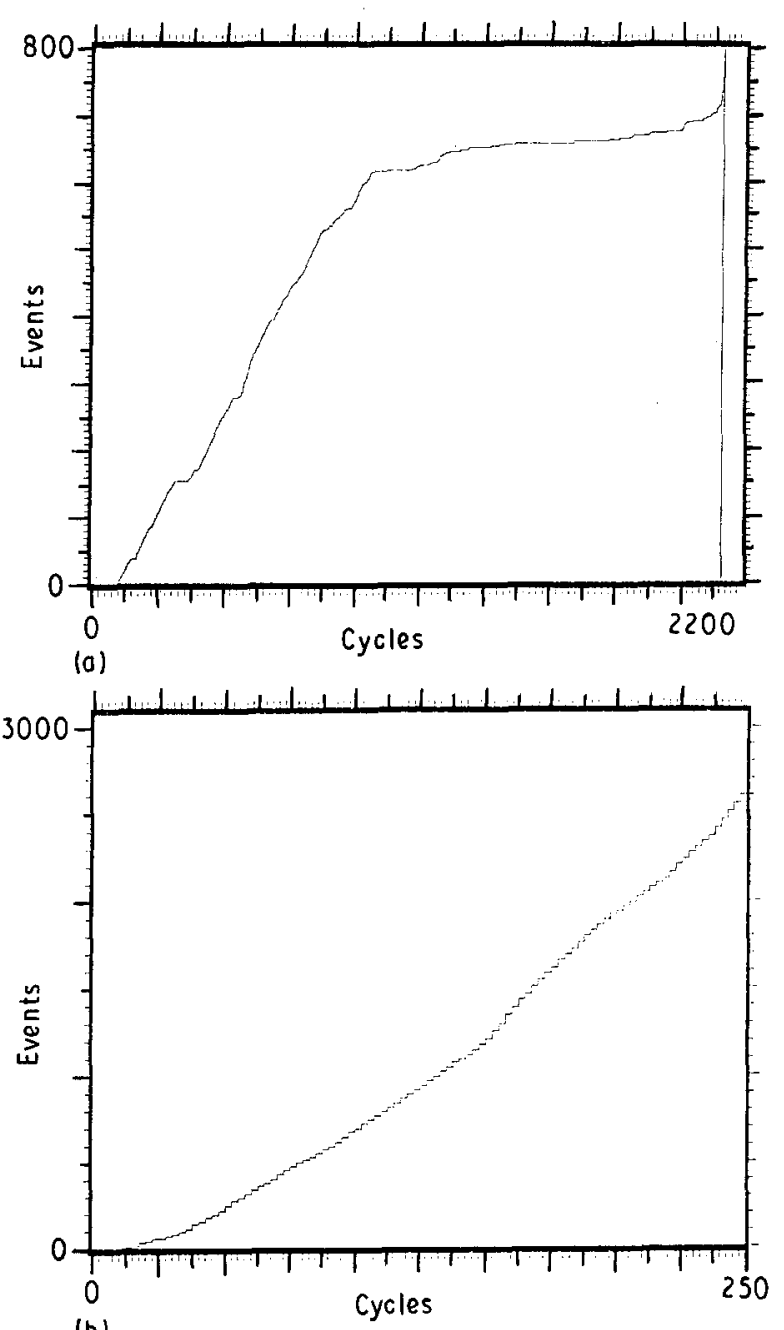

(b)

Figure 4 Curves of cumulative number of AE events as a function of cumulative number of fatigue cycles for $\mathrm{AE}$ events generated during rapid crack propagation in (a) equiaxed and (b) lamellar microstructures.

specimens probably result from thermally etched surface kinks, which serve as stress raisers. Events having low-level amplitudes $(<60 \mathrm{~dB})$ were generated at all locations, but events with higher amplitudes $(>70 \mathrm{~dB})$ were generated only in the reduced gauge section (Fig. 6). The average values of the other event intensities were also greatest in the reduced gauge section region (Table III). Therefore AE can be used with confidence to differentiate between damaged and undamaged areas.

The maximum intensities of the AE events generated during fatigue crack initiation in lamellar specimens were equivalent to the intensities generated during slow crack propagation $(A=75 \mathrm{~dB}$, En Cts $=750$, Cts $=600$, Dur $=3000 \mu \mathrm{s})($ Fig. $7 \mathrm{a}-\mathrm{d})$. Higher intensity events were generated at specific fatigue cycles $(N=22,3300,6000$ and 8000$)$. These relative maxima in intensity correspond to the increases in event rate seen on the $E-N$ curve for this specimen (Fig. 3b). The highest AE event intensities ( $\mathrm{Cts}=2100$, Dur $=5500 \mu \mathrm{s}$, En Cts $=2400)$ occurred during final fracture (Fig. 7a-d) and at the maximum stress (Fig. 7e-h). These trends in AE event intensity were also established for equiaxed microstructures [7]. For both equiaxed and lamellar microstructures, higher $\mathrm{AE}$ event intensities occurred at higher stress ranges
(Table IV). For both classes of microstructure, highlevel $\mathrm{AE}$ event intensities were generated at stresses other than the peak stress, implying that a number of $\mathrm{AE}$ sources may be active during the course of a fatigue cycle.

Events were separated based upon the stress ranges in which they were generated (Table IV). For the lamellar samples, almost half of the events were generated in the upper $5 \%$ of the stress range and over half were generated in the upper $20 \%$. These event distributions as a function of stress in lamellar specimens contrast with the results in equiaxed specimens, in which most $\mathrm{AE}$ events during slow crack propagation were generated at low stress levels. The fact that AE was generated at a different percentage of the peak stress for the two microstructures is another indication that different AE sources were operative in the two microstructures.

Inspection of the slow crack-propagation region of the $E-N$ curves (not shown here) reveals that events were generated at both intermediate (i.e. $60-80 \%$ of peak stress) and high (i.e. $80-100 \%$ of the peak stress) stress levels. Detailed examination of the $\mathrm{AE}$ data revealed that in a given fatigue cycle, most events were generated during the loading phase of the fatigue cycle. For consecutive loading cycles, events occurred, repetitively, at both constant single stresses (i.e. 70 or $100 \%$ of the peak stress) as well as over a range of stresses (i.e. $60-100 \%$ of the peak stress). The generation of $\mathrm{AE}$ events at a single, non-peak stress may indicate that the plastic flow which precedes crack propagation was detected. The generation of $\mathrm{AE}$ events at the peak stress and over a range of stress leading up to and including the peak stress may indicate that crack extension was detected.

\subsection{Correspondence between $A E$ and failure mechanisms}

The most important $\mathrm{AE}$ event intensity is amplitude, since it is directly related to the magnitude of an event. Amplitude is the event parameter which is best suited for developing distribution functions, since it is expressed on a logarithmic scale:

$$
\mathrm{d} B=20^{*} \log \left(V / V_{0}\right)
$$

In equiaxed microstructures, the macroscopic crack front advanced in a transgranular fashion, with ductile dimple formation (Fig. 8a). As crack length and $\Delta K$ increased, the dimples became more pronounced and the specimen ultimately failed through ductile overload and void coalescence. Lamellar microstructures exhibited a cleavage-like fracture morphology. As crack length and $\Delta K$ increased, fatigue striations developed (Fig. 8b). This transition in fracture morphology has been reported to occur at $\Delta K=13 \mathrm{MN} \mathrm{m}^{-3 / 2}[5,16]$. The average distance between striations was $5-7 \mu \mathrm{m}$, implying a rapid crack velocity. Cracks propagated along $\alpha / \beta$ interfaces until just before rapid fracture, when cracking became more intergranular and followed prior $\beta$-grain boundaries.

Lamellar microstructures consistently generated more $\mathrm{AE}$ than equiaxed microstructures. The combination of large grain size, continuous $\alpha / \beta$ interfaces, 


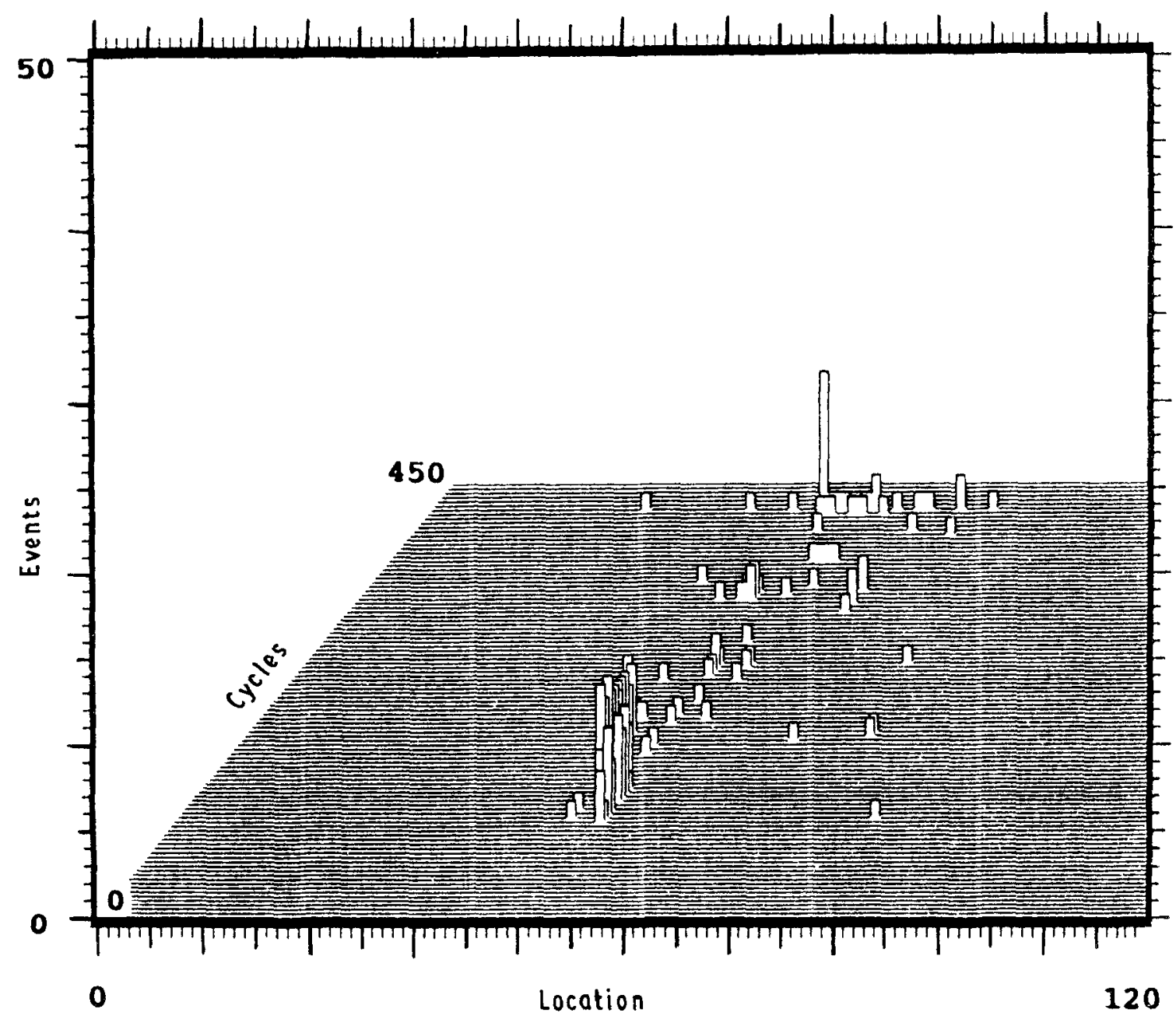

(a)

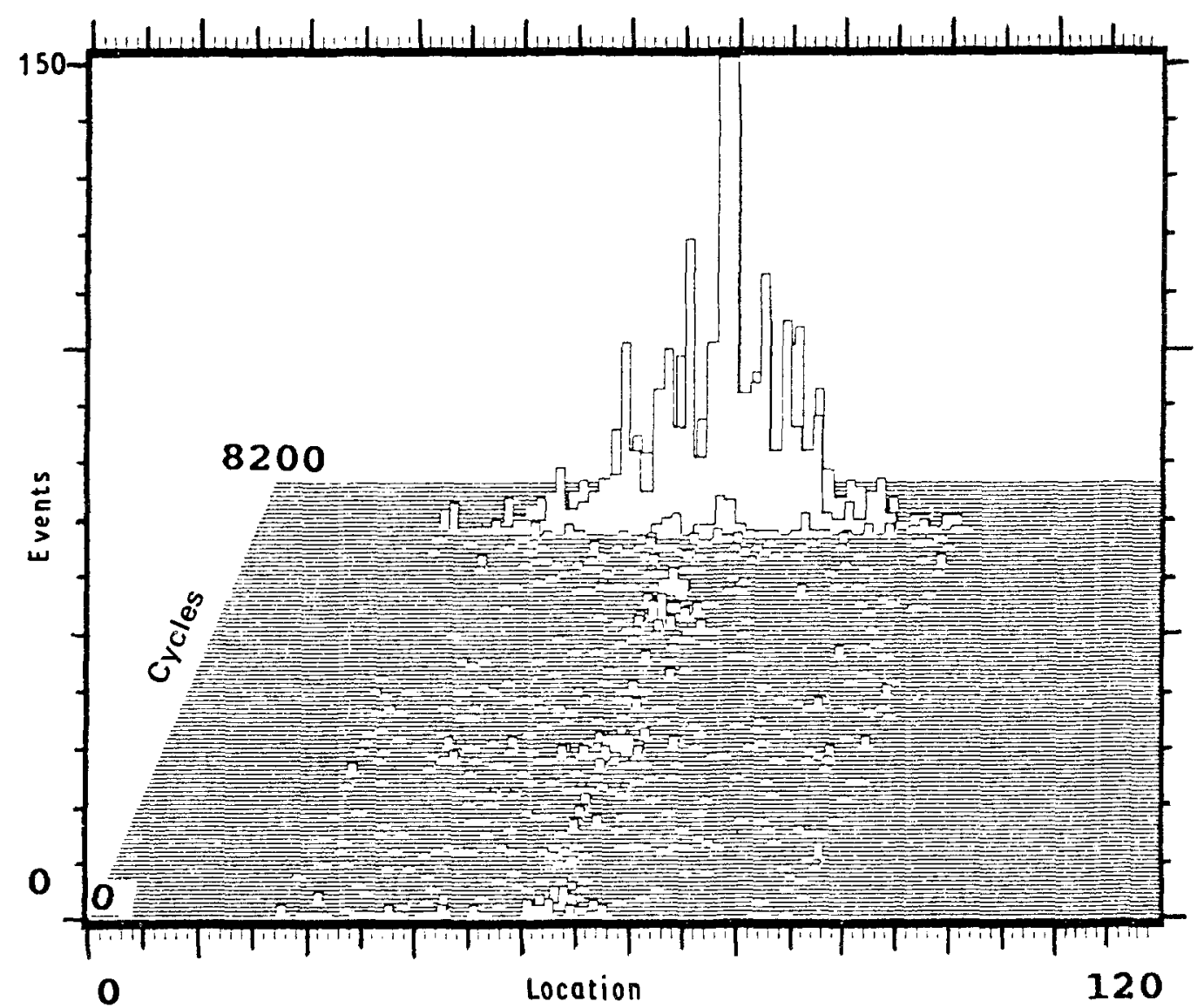

(b)

Figure 5 Location distribution histograms (LDH) for (a) equiaxed and (b) lamellar microstructures. 


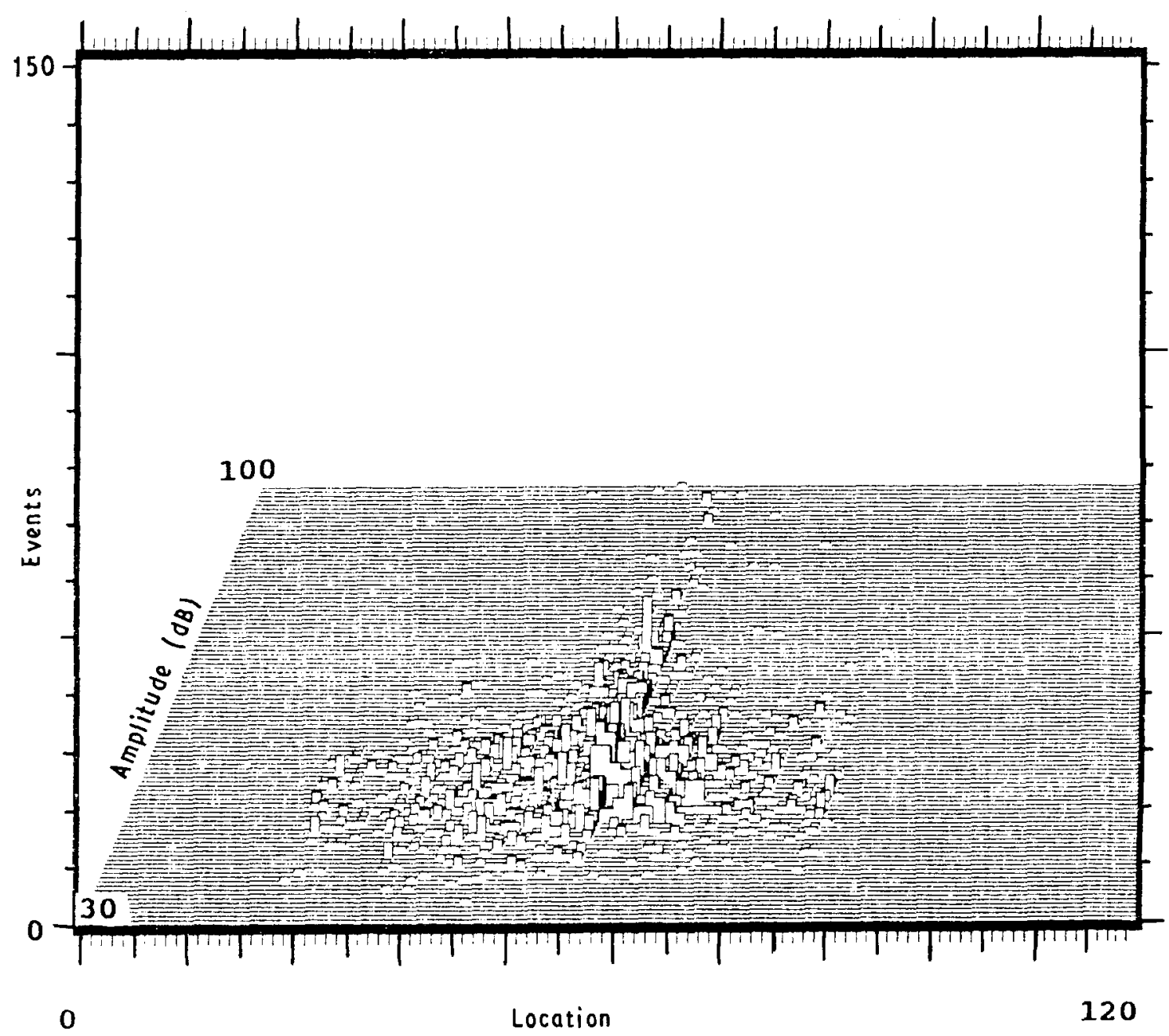

Figure 6 3D plot of generated $\mathrm{AE}$ events as a function of location and $\mathrm{AE}$ event amplitude for lamellar microstructure.

TABLE III Average AE event intensities for different locations on lamellar specimens

\begin{tabular}{lcllcc}
\hline Location $^{\text {a }}$ & Events & Amp (dB) & Cts (No) & Dur $(\mu \mathrm{s})$ & En Cts (No) \\
\hline $20 / 30$ & 77 & 50 & 27 & 132 & 16 \\
$70 / 80$ & 105 & 51 & 16 & 70 & 22 \\
$47 / 53$ & 667 & 58 & 91 & 464 & 124 \\
\hline
\end{tabular}

${ }^{a}$ The specimen shoulders are defined to be locations 0 and 100 , and the centre of the reduced gauge section is defined to be location 50 .

tortuous crack contour, cleavage and intergranular fracture are microstructural features known both in general $[17,18]$ and specifically for Ti-6Al-4V $[9,12$, 19], to cause more AE generation.

Table $\mathrm{V}$ summarizes the various fracture processes occurring in $\mathrm{Ti}-6 \mathrm{Al}-4 \mathrm{~V}$ and the maximum $\mathrm{AE}$ event amplitudes representing these mechanisms. Rather than indicating a range of amplitudes for a specific failure mechanism, an upper bound is reported. This is because multiple failure mechanisms may occur simultaneously and it is difficult to isolate a single event and associate it with a particular failure mechanism. At least twelve material and testing parameters influence the characteristics of the $\mathrm{AE}$ generated $[17,18]$. $\mathrm{AE}$ event intensities are dependent upon fracture mechanisms, which are dependent on material history, microstructure, stress and strain rate. In our experi- ments, microvoid coalescence, cleavage, fatigue striation formation, transgranular, intergranular and interphase fracture have all been observed, and these sources have been associated with specific AE event characteristics. The relationships between failure mechanisms and AE event amplitudes established in this study agree with those established by others $[13,14]$.

By choosing a time-base less than the time to complete one load cycle, it was possible to determine whether an $\mathrm{AE}$ event was generated during loading or unloading. Detailed examination of the stresses at which $\mathrm{AE}$ events were generated indicated that most events $(>90 \%)$ occurred during the loading phase of the load cycle. Therefore, two important trends in the $\mathrm{AE}$ data were repeatedly observed-AE was generated at low stresses, and during crack opening.

Separating events on the basis of stress level and whether they were generated during crack opening (damage or friction emission) or crack closure (friction emission) enabled the sources of $\mathrm{AE}$ to be classified into one of three general categories: plasticity, crack extension or friction. Events generated at low stress ranges (i.e. $0-50 \%$ of the peak stress) during the loading phase of a fatigue cycle may represent $\mathrm{AE}$ generated from crack faces grating over each other as the crack reopened. AE events generated at intermediate stresses (i.e. $50-80 \%$ of the peak stress) were 


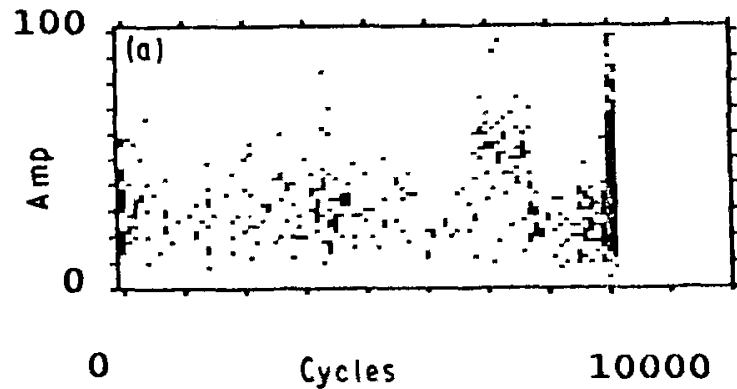

(a)

3000

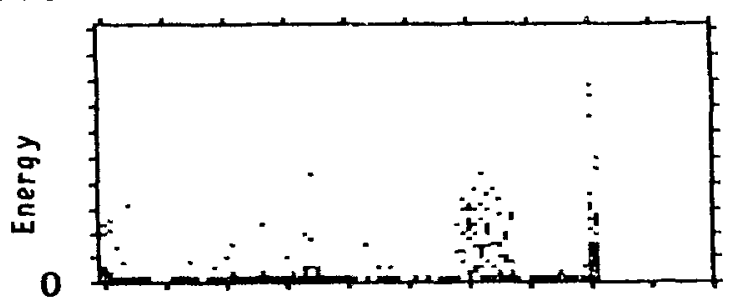

0

(b)

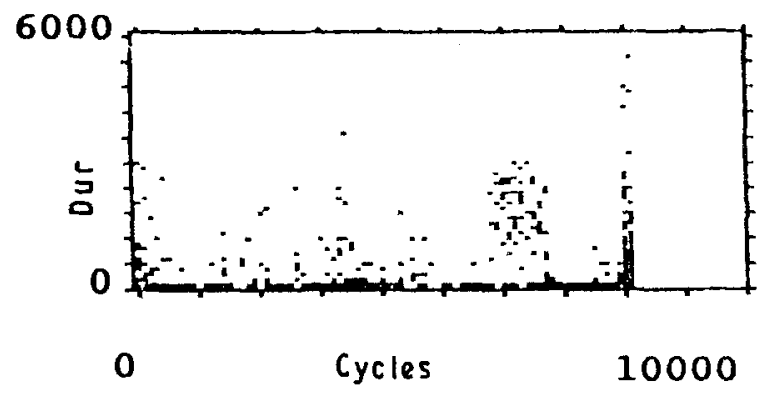

(c)

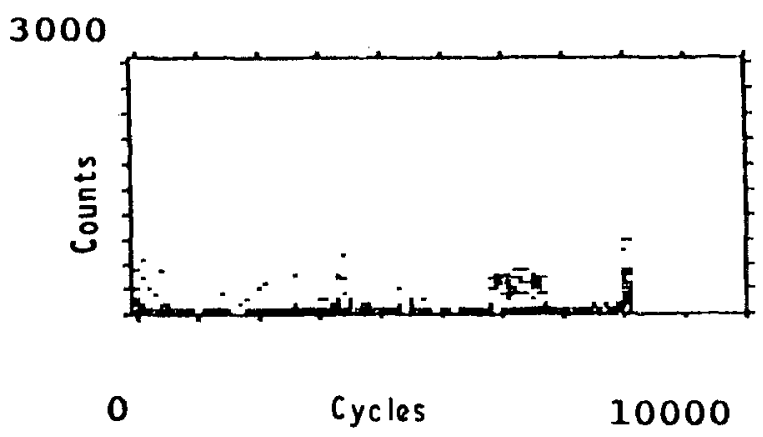

(d)

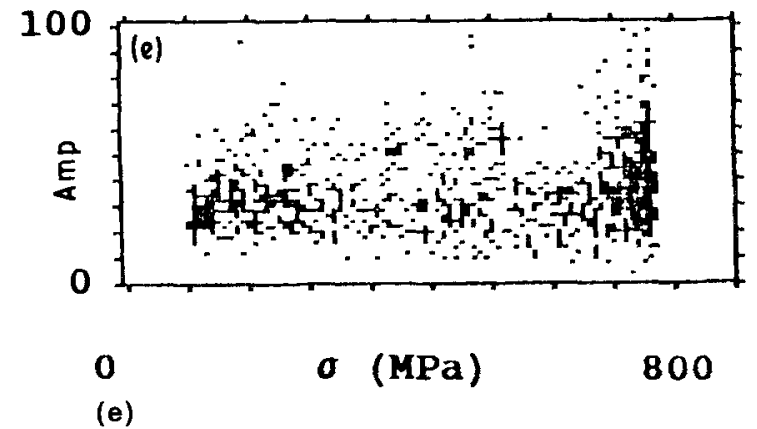

3000

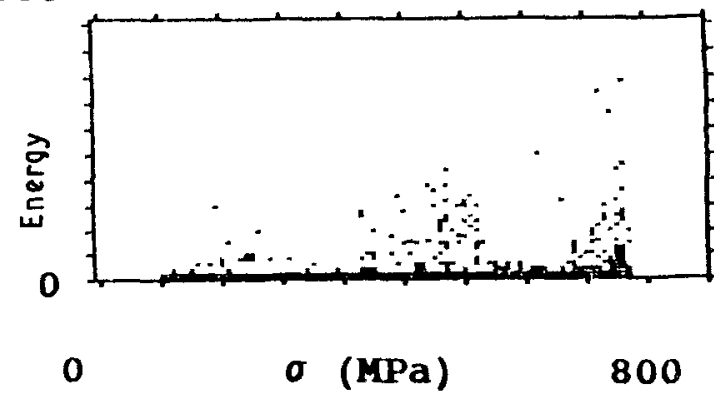

(f)

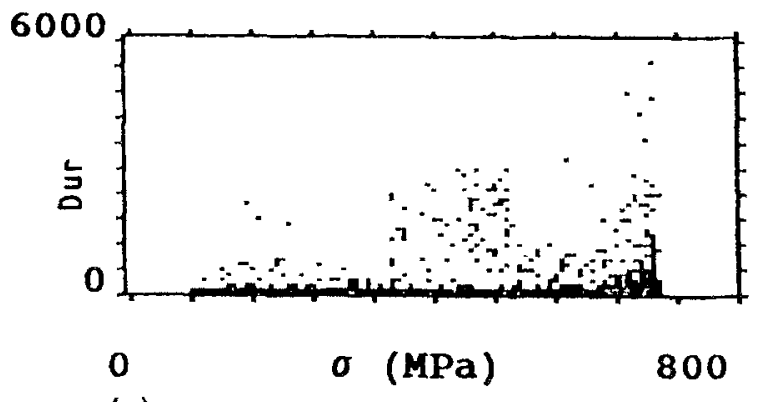

(g)

3000

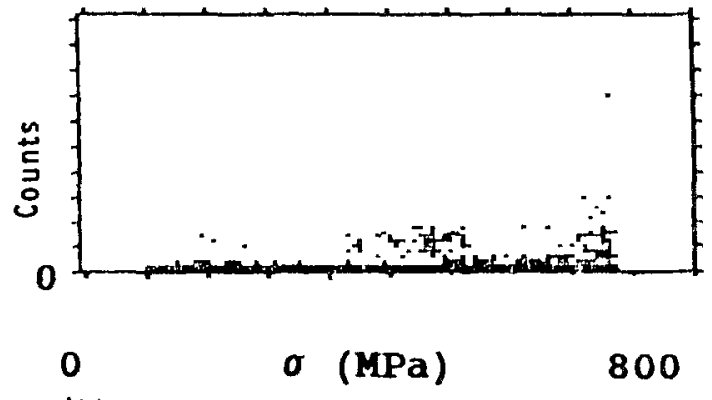

(h)

Figure 7 Point plots for lamellar specimen: (a-d) AE event intensities as a function of number of fatigue cycles; (e-h) AE event intensities as a function of stress.

assumed to be generated by plastic flow and yielding in the fracture process zone ahead of the crack tip [20]. AE events generated at peak stresses (i.e. $80-100 \%$ of the peak stress) were assumed to be generated by crack extension.

A precise distinction between crack extension and plastic flow was not possible, even with the aid of the closed circuit television. The differentiation between plastic flow and crack extension was based on whether events were generated at a single stress or over a range of stresses, within a given fatigue cycle. AE events generated at a single, non-peak stress were considered indicative of yielding in the plastic zone, whereas $\mathrm{AE}$ events generated at peak stresses, and over a range of stresses leading up to the peak stress, were believed to be indicative of crack extension. Optical observations revealed that in a given fatigue cycle, development of new crack faces was preceded by the expansion of the plastic zone. It was also observed that once crack extension started in a given fatigue cycle, it continued until the peak stress was reached, at which time crack blunting occurred.

AE events generated at the peak stress had higher intensities than events generated at intermediate stresses. This is because crack extension is generally much louder than the plastic flow which precedes it [17]. In 
TABLE IV Average intensities of AE events generated at different stress ranges

\begin{tabular}{|c|c|c|c|c|c|}
\hline Range $\left(\% \sigma_{\max }\right)$ & Events & $A m p(d B)$ & Cts (No) & $\operatorname{Dur}(\mu \mathrm{s})$ & En Cts (No) \\
\hline \multicolumn{6}{|l|}{ Equiaxed } \\
\hline $0-100 \%$ & 125 & 52 & 17 & 81 & 16 \\
\hline $0-60 \%$ & 109 & 52 & 13 & 60 & 12 \\
\hline $0-80 \%$ & 114 & 52 & 13 & 59 & 12 \\
\hline $80-100 \%$ & 11 & 56 & 57 & 312 & 62 \\
\hline $95-100 \%$ & 5 & 60 & 54 & 284 & 70 \\
\hline \multicolumn{6}{|l|}{ Lamellar } \\
\hline $0-100 \%$ & 1407 & 56 & 87 & 350 & 125 \\
\hline $0-60 \%$ & 425 & 54 & 38 & 167 & 66 \\
\hline $0-80 \%$ & 606 & 55 & 67 & 342 & 91 \\
\hline $80-100 \%$ & 775 & 56 & 104 & 444 & 153 \\
\hline $95-100 \%$ & 590 & 56 & 115 & 358 & 175 \\
\hline
\end{tabular}
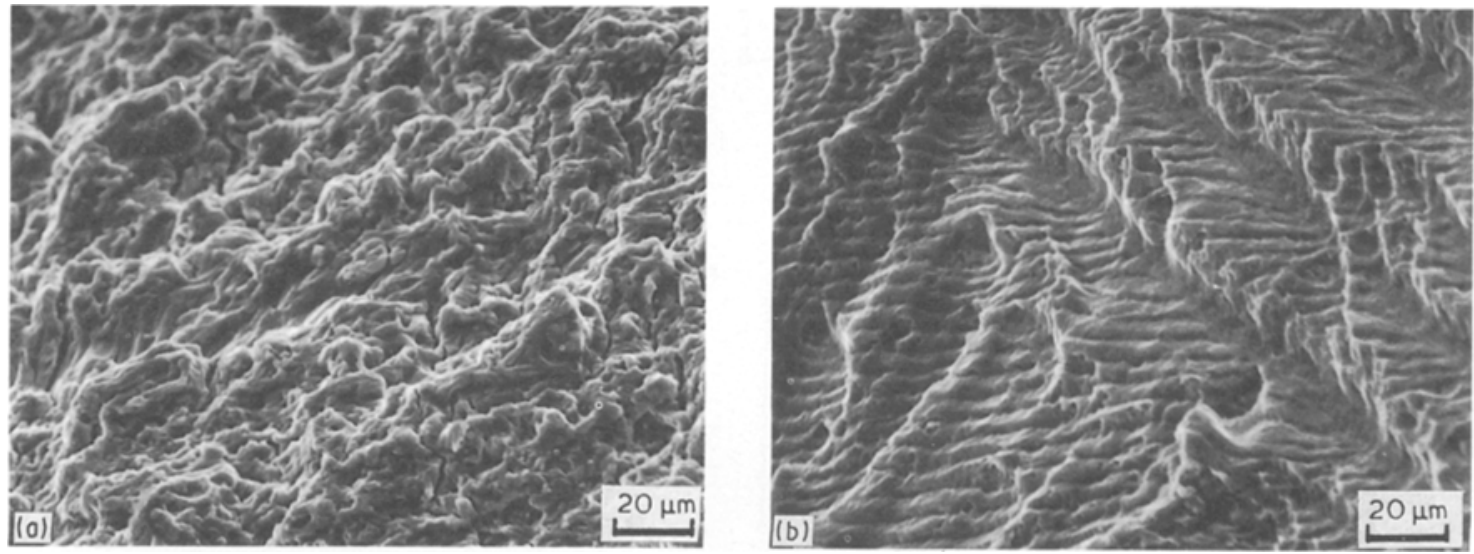

Figure 8 SEM photographs of fracture surfaces of (a) equiaxed and (b) lamellar microstructures $(\times 640)$.

TABLE V Correspondence between AE sources and peak AE event amplitudes in Ti-6Al-4V

\begin{tabular}{lc}
\hline AE source mechanism & Amplitude $(\mathrm{dB})$ \\
\hline Microvoid coalescence & $<100$ \\
$\alpha / \beta$ Interface cracking & $<80$ \\
Fatigue striations & $<80$ \\
Cleavage & $<80$ \\
Transgranular cracking & $<70$ \\
Intergranular cracking & $<100$ \\
Plastic flow & $<65$ \\
Friction & $<55$ \\
\hline
\end{tabular}

contrast, though, AE studies on steels have shown that, in some cases, it is plastic-zone extension and not crack extension which is detected. Steels undergoing ductile fracture may be classified into two categories: high strength/low toughness, in which most $\mathrm{AE}$ is generated from crack propagation; and low strength/ high toughness, in which most $\mathrm{AE}$ is generated from plastic zone extension [21]. Titanium alloys, which have both high strength and high toughness, generate emission from both plastic zone extension and crack extension.

\section{Summary and conclusions}

1. The three stages of fatigue (i.e. crack initiation, slow crack propagation, rapid crack propagation) were detected with $\mathrm{AE}$, enabling failure to be readily anticipated for both equiaxed and lamellar microstructures. AE can also be used to differentiate between damaged and undamaged specimen areas.

2. Lamellar microstructures generated one to two orders of magnitude more $\mathrm{AE}$ events than equiaxed microstructures. The combination of larger grain size, more continuous $\alpha / \beta$ interfaces, more tortuous crackfront geometry, cleavage and intergranular fracture in lamellar microstructures accounts for the greater amount of $\mathrm{AE}$ generated.

3. For both equiaxed and lamellar microstructures, the intensities of the AE events generated during each of the three stages of fatigue could be ranked as follows: rapid crack propagation $>$ crack initiation $>$ slow crack propagation. AE event intensities also increased with increasing stress.

4. For lamellar microstructures, most AE events were generated in the upper $20 \%$ of the stress range, whereas in equiaxed microstructures, most $\mathrm{AE}$ events were generated at lower stresses.

5. AE was generated during crack opening and also at low stresses. AE events having high-level intensities were also generated at stresses other than the peak stress. This is because in titanium alloys, which have both high strength and toughness, $\mathrm{AE}$ events are generated from both plastic-zone extension and crack extension. 


\section{Acknowledgements}

This work was made possible by a grant in aid from DePuy, Inc., Warsaw, IN 46580. The assistance of Shahrokh Ghaffari is gratefully acknowledged.

\section{References}

1. C. A. Stubbington, AGARD Conf. Proc. No. 185 (1976) 3.1.

2. H. MARGOLIN, J. C. WILliams, J. C. CHESNUTT and G. LUTJERING, in "Titanium " 80 Science and Technology", Proceedings of the 4 th International Conference on Titanium, edited by $\mathrm{H}$. Kimura and $\mathrm{O}$. Izumi (The Metallurgical Society of AIME, Warrendale, PA, 1980) p. 169.

3. M. PETERS, A. GYSLER and G. LUTJERING, in ibid p. 1777.

4. G. LUTJERING and A. GYSLER, in "Titanium, Science and Technology", Proceedings of the 5th International Conference on Titanium, edited by G. Lutjering, U. Zwicker and W. Bunk (Deutsche Gesellschaft Fur Metallkunde, Oberursel, West Germany, 1985) p. 2065.

5. P. E. IRVING and C. J. BEEVERS, Mater. Sci. Engng $\mathbf{1 4}$ (1974) 229.

6. D. H. KOHN, P. DUCHEYNE and J. AWERBUCH, in "Titanium Science Technology and Applications", Proceedings of the 6th World Conference on Titanium, edited by P. Lacombe, R. Tricot and G. Beranger (Les Editions de Physique, Paris, 1989) p. 789.

7. D. H. KOHN, P. DUCHEYNE and J. AWERBUCH, J. Mater. Sci., in press (1990).

8. H. TANAKA and R. HORIUCHI, Scripta Met. 9 (1975) 777.

9. J. R. KENNEDY, ibid. 16 (1982) 525.

10. G. CHANCY, B. PIGE and H.PAGUETON, in "Titanium, Science and Technology", Proceedings of the 5th International Conference on Titanium, edited by G. Lutjering, U. Zwicker and W. Bunk (Deutsche Gesellschaft Fur Metallkunde Oberursel, West Germany, 1985) p. 1891.

11. M. A. FRIESEL and S. H. CARPENTER, Met. Trans, $A$ 15A (1984) 1849.
12. T. KISHI, H. S. PARK, R, HORIUCHI, T. KAKIMI, M. NAKANOSE and T. TANABE, in "Titanium ' 80 Science and Technology", Proceedings of the 4th International Conference on Titanium, edited by $\mathrm{H}$. Kimura and $\mathrm{O}$. Izumi (The Metallurgical Society of AIME, Warrendale, PA, 1980) p. 1709.

13. T. KISHI, T. OHIRA and H. OHYAMA, in "Titanium Science and Technology", Proceedings of the 5th International Conference on Titanium, edited by G. Lutjering, U. Zwicker and W. Bunk (Deutsche Gesellschaft Fur Metallkunde, Oberursel, West Germany, 1985) p. 2039.

14. S. YUYAMA, T. KISHI, Y. HISAMATSU and T. KAKIMI in "Progress in Acoustic Emission", Proceedings of the 6th International AE Symposium, edited by M. Onoe, K. Yamaguchi and T. Kishi (The Japanese Society for NonDestructive Inspection, Susono, Japan, 1982) p. 126.

15. ASTM standard F136-84, in "Annual Book of ASTM Standards, Vol 13. 01: Medical Devices" (ASTM, Philadelphia, 1987) p. 28.

16. A. YUEN, S. W. HOPKINS, G. R. LEVERANT and C. A RAU, Met. Trans. 5 (1974) 1833.

17. H. L. DUNEGAN and A. T. GREEN, Mater. Res. Stand. 11 (1971) 21

18. C. R. HEIPLE and S. H. CARPENTER, in "Acoustic Emission", edited by J. R. Matthews (Gordon \& Breach, New York, 1981) p. 14

19. Z. ZUMING, B. SEN, F. SHIYU and Z. HONGTIAN, in "Progress in Acoustic Emission II", Proceedings of the 7th International AE Symposium, edited by M. Onoe, K. Yamaguchi and H. Takahashi (The Japanese Society for NonDestructive Inspection, Zao, Japan, 1984) p. 218.

20. T. OHIRA, T. KISHI and R. HORIUCHI, in Proceedings of the 5th International AE Symposium (The Japanese Society for Non-Destructive Inspection, Tokyo, 1980) p. 137.

21. H. N. G. WADLEY, C. B. SCRUBY and J. H. SPEAKE, Int. Met. Rev. 2 (1980) 41.

Received 8 January

and accepted 25 February 1991 